happen little or not at all in Sweden. Nevertheless, the public and the media there are still concerned about commercial pressure on doctors, and ironically my visit to Sweden coincided with an enormous medical congress that is held each year and attended by half of all the doctors in Sweden. There are some 1500 seminars, symposia, and lectures, but there are also immense exhibitions of drugs and medical equipment. The companies are careful to give away nothing more expensive than coffee or ice cream, but still some of the journalists who visit the fair are struck by the commercial overtones.

While I was in Sweden, one of the two Stockholm newspapers carried a report on the fair under the title "Doctors' Kivik fair." $\underline{\underline{T}}$ The Kivik fair is a famous cattle fair held each year to the accompaniment of strip shows and all sorts of salacious "tingletangle" as the Swedes call it. The report elaborated on the "greedy looks" of the doctors and on their "expensive suitcases bleached by the sun they have encountered attending conferences in Tokyo, San Francisco, Honolulu, and Rio. . . " Doctors do truly have to be very careful with their image (15 December, p 1699).

I am especially grateful to Professor Lars Böttiger for help in preparing this article.

\title{
Prescribing: the power to set limits
}

\author{
J M HARDING, M MODELL, S FREUDENBERG, \\ M WOJCIECHOWSKI, G D YUDKIN \\ R MACGREGOR, J NICOLAS REA, \\ C A STEEN,
}

\begin{abstract}
This paper discusses drawing up a restricted list of $\mathbf{2 4 5}$ drugs for use in an inner London group practice, based on a review of prescribing patterns in November 1982. The likely impact of the recent proposals by the Department of Health and Social Security to limit drugs available for prescription under the National Health Service on this project and on patient care is considered. We conclude that generic prescribing and a limited list of drugs may improve the quality of prescribing and be the only way to curb prescribing costs but that a limited list should be flexible, responsive to patients' needs, and applied to all prescribing. There should also be a mechanism for consumer feedback and regular revision of the list.
\end{abstract}

\section{Introduction}

Prescribing is a focal point of contacts between doctors and patients and one indicator of the quality of medical care given. ${ }^{1-3}$ It is also relevant to the marketing strategies of drug companies and media disclosures about the hazardous effects of specific drugs. Most recently prescribing has become the target of government attempts to limit National Health Service expenditure. ${ }^{4}$

Critics have called for limits to the range and cost of drugs prescribed, and some have argued strongly for "generic substitution." The Greenfield report proposed that pharmacists be allowed to substitute cheaper generic preparations for more expensive brand name products unless otherwise stated by the prescribing doctor. ${ }^{5}$ This recommendation was seen by some to threaten both the profits of drug companies and the clinical autonomy of the medical

Kentish Town Hall Health Centre, London NW5 2AJ

J M HARDING, BA, MSC, research officer

M MODELL, MRCP, FRCGP, general practitioner and senior clinical lecturer in general practice, University College London

$S$ FREUDENBERG, MB, MRCGP, general practitioner

R MACGREGOR, MBBCHIR, MRCGP, general practitioner

J NICOLAS REA, MD, MRCGP, general practitioner

C A STEEN, MB, MRCGP, general practitioner

$M$ WOJCIECHOWSKI, MB, MRCGP, general practitioner

G D YUDKIN, MB, DCH, general practitioner

Correspondence to: Jennifer M Harding, James Wigg Practice, Kentish Town Health Centre, 2 Bartholomew Road, London NW5 2AJ practitioner. Though drug companies argued that generic preparations were not equivalent to specific brand name products, the BMA supported the recommendations of the Greenfield report provided they were not compulsory.

The recent proposals by the Department of Health and Social Security have side stepped the controversial issue of "generic substitution," which would potentially apply to every prescription, and introduced a restricted list for eight categories of drugs. ${ }^{4}$ The effect of these proposals will be to limit the service available to patients under the NHS by making the full range of drugs available only to those who are able and willing to pay.

Hospitals have for many years used drug formularies to limit the range and cost of prescribing. Pharmacy and therapeutics committees select which drugs hospitals buy, and these alone are available to the prescribing physician. Apart from the mass of advertising publications produced by the drug companies and the results of drug trials published in the medical journals, some attempts are made by the DHSS to influence the quality and type of drugs prescribed by general practitioners.

Prescribers' Fournal, Drug and Therapeutics Bulletin, drug cost histograms, and publications from the University of Southampton's Drug Surveillance Research Unit are distributed free to general practitioners. Prescribing patterns in general practice have been described, ${ }^{67}$ and information on prescribing and morbidity has been used for critical review to improve prescribing habits. ${ }^{8-10}$ Harris $e t$ al showed a selective reduction in prescribing by a group of general practitioners who, after receiving information about their prescribing decisions, prescribed fewer drugs and more often chose generic preparations. " Clinical pharmacologists have worked with a group of general practitioners to produce a booklet recommending treatment policies for common conditions and have attempted to assess the effects of peer review and discussion on prescribing patterns. ${ }^{12}$ Some general practitioners have compiled their own restricted list of drugs. ${ }^{1314}$ The encouragement of general practitioners to engage in self audit before decisions and definitions of "appropriate prescribing" are imposed from outside the medical profession has, however, been overtaken by events. ${ }^{15}$

We drew up a restricted list of drugs for use in an inner London group practice with a list of over 13000 patients. This was one outcome of a larger project to review and change antibiotic prescribing. The doctors (seven partners and two trainees) made a carbon copy of all prescriptions for 21 days in December 1982, and this forms the data base of the work discussed here. The doctors were presented with details of the frequency and range of items prescribed and decided to draw up a restricted list of about 250 different preparations to guide everyday prescribing practice. 


\section{Design and methods}

Each doctor was presented with the full list of drugs prescribed during the 21 days (table I) and agreed to take one or two categories and draw up a limited list based on need, economy, and suitability (table II). These lists of drugs were then matched with drugs of the same category prescribed in the study and the lists presented to the doctors for comment. After discussion and criticism the list was revised, discussed again, and further amendments made. This refinement was applied to all categories of drugs in the British National Formulary. A practice formulary was produced after discussion with the professor of clinical pharmacology at University College. The researcher was responsible for coordinating this activity and ensuring that all doctors completed the tasks allotted to them. A regular record of prescribing costs was requested from the Prescription Pricing Authority. The average cost per prescription issued in the practice in December 1983 was $£ 3.41$, compared with an average of $£ 3.35$ for the area and $£ 3.46$ for England.

TABLE I-Process of constructing a practice formulary

1982 October-November Carbon copies of all prescriptions (repeats and consultation) collected. ( 35 days)

1983 January-April

Prescriptions for last 21 days checked against doctor's written records, appointments, visits, night calls, and repeat prescription registers and analysed.

1983 May

Full list of drugs prescribed given to doctors meeting to discuss prescribing. * Decided to draw up restricted list of drugs for everyday prescribing. Doctors each chose a category.

1983 June Meeting to consider and amend individual lists, comparing with those prescribed during the study period.

$1983 \mathrm{July} \quad$ Meeting to discuss revised lists and allocate further categories of drugs

1983 September Meeting to discuss revised
(using BNF classification).

1983 December 1984 January

1984 April May
June
July Meeting to discuss each category at length and revise.

Meeting for further discussion of revised lists. Draft formulary produced: Meeting to discuss and amend draft. Draft sent to professor of clinical pharmacology

Began monitoring prescribing costs

Meeting with professor of clinical pharmacology. Draft amended. Second draft produced.

Meeting approved Formulary for use in pilot study.

1984 September-December Corrections, typesetting, and printing in loose leaf form.

1985 January (for 2 l days)

Prepilot monitoring of prescriptions

*All general practitioners and the researcher were present at each meeting.

TABLE II-Criteria used for selecting drugs for practice formulary

\begin{tabular}{ll}
\hline Criteria & $\begin{array}{l}\text { Where many similar drugs are available one drug is chosen above the } \\
\text { others on the basis of: } \\
\text { The drug achieves the desired effect in a manner suitable (see C to the } \\
\text { patient. Evidence of effectiveness is based on clinical experience, pub- } \\
\text { lished sources, and recommendations of "experts". }\end{array}$ \\
(A) Need & $\begin{array}{l}\text { The cheapest drug. } \\
\text { The drug is acceptable to patients, having minimal side effects, being } \\
\text { convenient to take (in terms of regularity of dose and rate). }\end{array}$
\end{tabular}

\section{Results}

During the 21 day period 2336 patients received a prescription either as a result of direct contact with the doctor (1558 patients) or as a request for a repeat prescription ( 778 patients). A prescription was issued in $64 \%$ of all direct contacts, a rate similar to the national average. Copies of prescriptions were checked against appointment, visit, night call, and repeat prescription registers; doctors had made copies of $91 \%$ of prescriptions in consultations; the receptionists had made copies of $97 \%$ of repeat prescriptions. Five hundred and twenty three differently named drugs were prescribed. Generic prescribing, which accounted for $29 \%$ of the total, was most often done in direct consultations (table III). The groups of drugs that were prescribed most often were psychotropics, followed by antibiotics and drugs acting on the respiratory system (figure). Almost three quarters of psychotropic drug prescriptions were for 17 differently named benzodiazepines (including proprietary drugs). A quarter of all patients who received a repeat prescription were prescribed a benzodiazepine, and three quarters of these were women. The preparations that were prescribed most often were salbutamol and diazepam (table IV).

The doctors spent 18 months reviewing their prescribing and generating a formulary, which included just over half the number of different items prescribed during the 21 day period (table III). Over $80 \%$ of the drugs included were generic preparations, chosen to the exclusion, when possible, of brand name products. In compiling the list they took into account their own preferences and prejudices and those expressed by patients. Differences
TABLE III-Number of drug preparations in November 1982 and those included in the practice formulary

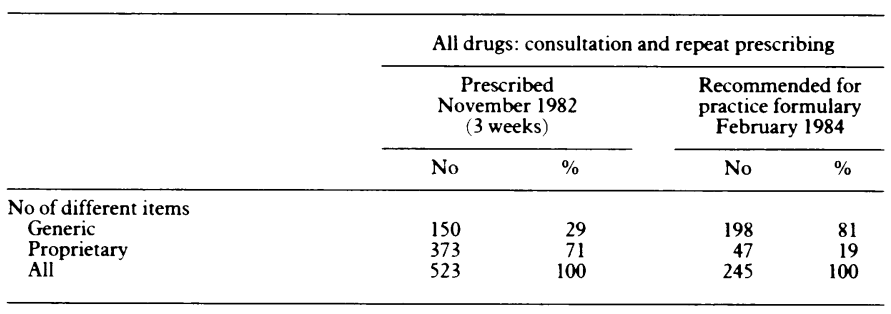

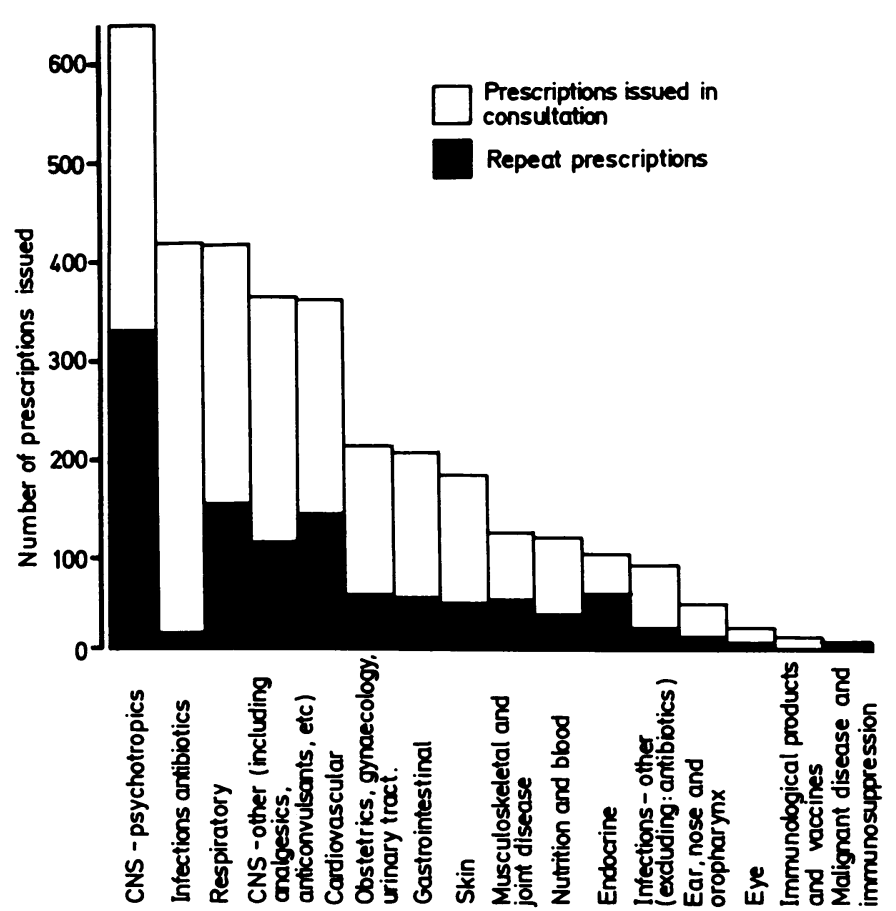

Number of prescriptions issued during 21 days according to drug category (taken from the British National Formulary classification).

TABLE IV-Most frequently prescribed drugs

\begin{tabular}{lc}
\hline \multicolumn{1}{c}{$\begin{array}{c}\text { Drug preparation } \\
\text { (including proprietary name drug) }\end{array}$} & $\begin{array}{c}\text { No of times prescribed in consultation } \\
\text { and as repeat prescriptions }\end{array}$ \\
\hline Salbutamol (Ventolin) & 169 \\
Diazepam (Valium) & 147 \\
Amoxycillin (Amoxil) & 110 \\
Paracetamol (Calpol, Panadol) & 100 \\
Nitrazepam (Mogadon) & 95 \\
1\% HC cream (Neo-cortef, Nystaform) & 72 \\
Temazepam (Normison, Euhypnos) & 60 \\
Bendrofluazide (Neo-Naclex K) & 60 \\
\hline
\end{tabular}

among doctors in treatment practices were evident throughout and lively debate arose between the older partners, who favoured longer established preparations, and the trainees, who argued for newer drugs. Strong disagreement was rare, and when it occurred the issue was debated until one view prevailed and the drug was included or rejected. The doctors decided to restrict new prescribing to formulary preparations. These would be reviewed very six months, a task made easy by the use of a word processor. Patients would continue on excluded drugs if they had been regularly prescribed previously, although efforts would be made to persuade them to accept a formulary preparation. Also, drugs not included in the formulary might be prescribed if they had been initiated in hospital and requested as repeat medication.

\section{Discussion}

There is nothing new about setting limits to prescribing. Hospitals in the United Kingdom and North America have used national drug formularies for many years, and several countries 
have schemes for limited drug prescribing. Similar initiatives from general practice are few, however, and from a British government department are novel. So, who should set limits and which criteria should be used?

The recent government proposals do more than interfere with professional autonomy. They call into question the availability and appropriateness of a comprehensive health service, independent of the ability to pay, and the relative role of state and profession as arbiters in matters of health and illness.

The exclusion in the DHSS draft proposals of certain drugs from NHS prescribing may leave no equivalent preparation available. The process of finding a suitable drug for a chronically ill patient might have been lengthy, and similar alternatives may not be acceptable to patients because they do not have the desired effect, are unpalatable, or have unpleasant side effects.

There is an urgent need to review and limit prescribing and use generic equivalents in most instances. The problem is to find a satisfactory method of doing so. The effects of limited drug lists depend on how and by whom they are compiled and how doctors' compliance is maintained and monitored. In the absence of legislation compliance is most likely if the prescribing doctors have been actively concerned in constructing the list. General practitioners seem willing to change the range of drugs that they prescribe when presented with information about prescribing patterns and even to reduce that level of prescribing. ${ }^{811}$ Limited lists, which are the outcome of negotiation among general practitioners, can be more finely tuned to meet the needs of patients and doctors. If used flexibly they can accommodate patients who depend on specific drugs. Regular review is necessary to ensure that too much "flexibility" does not undermine the principle of a limited list.

Limited lists may affect which drugs are given but will not necessarily lead to "better" prescribing. We need to question the appropriateness of decisions to prescribe and doctors' and patients' dependence on drug treatment. For each drug prescribed we should ask whether it was necessary to prescribe at all, if that drug is the most effective for that condition, whether it has been in use long enough for likely side effects to be known, whether there are any contraindications to prescribing it for a particular patient (for example in pregnancy), whether interactions with other drugs the patient takes are likely, and whether there is a cheaper equivalent preparation. The influence of various social and cultural factors on decisions to prescribe has been widely reported and is of considerable importance. ${ }^{16-20}$

Changes in prescribing will profoundly affect patients. The process of constructing a formulary needs to be linked with providing information and advice to patients about the changes proposed and a method of ascertaining and incorporating patients' responses. We plan to ask our health centre users' group to consider the formulary, and, when they make their routine surveys of patients' views of the service provided, to inquire about patients' views on the use of a limited list of drugs. Patients' views will also be monitored by other members of the practice team, especially the receptionists, and will be taken into account when the formulary is revised. We will continue to request regular records of prescribing costs.

Such an initiative is likely to be impeded by the recent government proposals. If these are implemented many of the drugs included in our formulary will not be available on the NHS after April 1985 (see Appendix). Whyte, who already uses a restricted drug list, estimates that a gradual changeover of patients from DHSS proposed "blacklisted" drugs to alternative preparations would require 25 extra appointments a week. ${ }^{14}$

Reviewing and discussing factors that influence prescribing, together with reassessing the items prescribed, is an educative process of benefit to doctors and patients. Generic prescribing and a limited list for all drugs (not just the categories dealt with in the DHSS proposals) may improve the quality of prescribing and be the only way to curb prescription costs, which are inflated by some drug companies. But a restricted list must be flexible and responsive to patients' needs, and there should be a mechanism for consumer feedback. It should apply to all prescribing, as a division between private and NHS prescriptions furthers a two class system of health care in which the NHS may be seen as second class. Certain investigations and treatments are already influenced by ability to pay. If certain drugs are not suitable for prescribing on the NHS perhaps they are not suitable at all.

We thank Professor Laurence of University College, London for helpful advice on the draft practice formulary; Mrs H Forman, practice manager at the James Wigg Practice, for criticism of the paper; and Shirley Beukers, course organiser, GP Unit, University College, for producing and correcting the manuscript.

\section{Appendix}

Excerpts from the DHSS provisional limited list of drugs available for prescription on the NHS compared with those listed in the James Wigg practice formulary

\begin{tabular}{|c|c|c|}
\hline \multicolumn{2}{|c|}{ DHSS provisional list } & \multirow{2}{*}{ James Wigg practice formulary } \\
\hline $\begin{array}{l}\text { Available for } \\
\text { prescription }\end{array}$ & $\begin{array}{l}\text { Not available for } \\
\text { prescription }\end{array}$ & \\
\hline \multicolumn{3}{|l|}{ Antacids } \\
\hline \multirow[t]{3}{*}{$\begin{array}{l}\text { Aluminium hydroxide } \\
\text { mixture and tabs }\end{array}$} & All other antacids & $\begin{array}{l}\text { Aluminium hydroxide mixture and } \\
\text { tabs }\end{array}$ \\
\hline & & Magnesium carbonate mixture \\
\hline & & $\begin{array}{l}\text { Magnesium trisilicate mixture and } \\
\text { compound tabs }\end{array}$ \\
\hline \multicolumn{3}{|l|}{$\begin{array}{l}\text { Compound magnesium } \\
\text { trisilicate oral powder }\end{array}$} \\
\hline \multicolumn{3}{|l|}{$\begin{array}{l}\text { Compound sodium } \\
\text { bicarbonate tabs } \\
\text { (soda mint tabs) }\end{array}$} \\
\hline \multicolumn{3}{|l|}{$\begin{array}{l}\text { Magnesium trisilicate } \\
\text { mixture }\end{array}$} \\
\hline \multicolumn{3}{|l|}{ Laxatives } \\
\hline Glycerol supps & All other laxatives & $\begin{array}{l}\text { Liquid paraffin and magnesium } \\
\text { hydroxide mixture }\end{array}$ \\
\hline \multirow{7}{*}{$\begin{array}{l}\text { Methylcellulose } \\
\text { granules }\end{array}$} & & Ispaghula husk \\
\hline & & Bisacodyl tabs and syrup and supps \\
\hline & & Danthron caps and liquid \\
\hline & & Senna tabs and granules \\
\hline & & Lactulose elixir or syrup \\
\hline & & Glycerol supps \\
\hline & & Dioctyl (sodium sulphosuccinate) \\
\hline \multicolumn{3}{|c|}{ Benzodiazepine sedatives and tranquillisers } \\
\hline Diazepam & $\begin{array}{l}\text { All other benzodiazepine } \\
\text { sedatives and tranquillisers }\end{array}$ & Diazepam \\
\hline Nitrazepam & & Temazepam \\
\hline \multirow[t]{2}{*}{ Temazepam } & & Chlordiazepoxide \\
\hline & & Nitrazepam \\
\hline \multicolumn{3}{|c|}{ Analgesics for mild to moderate pain } \\
\hline Aspirin tabs & All other analgesics & Aspirin tabs \\
\hline Dispersible aspirin tabs & $\begin{array}{l}\text { including compound } \\
\text { analgesic preparations }\end{array}$ & Aspirin EC tabs \\
\hline \multicolumn{2}{|l|}{$\begin{array}{l}\text { Paediatric dispersible } \\
\text { aspirin tabs }\end{array}$} & Aspirin tabs (dispersible) \\
\hline \multicolumn{2}{|l|}{ Paracetamol tabs } & Aspirin tabs paediatric dispersible \\
\hline \multirow{4}{*}{\multicolumn{2}{|c|}{ Paediatric paracetamol elixir }} & $\begin{array}{l}\text { Paracetamol tabs and soluble } \\
\text { paracetamol tabs }\end{array}$ \\
\hline & & Paediatric paracetamol elixir \\
\hline & & Paracetamol and codeine tabs \\
\hline & & Codeine phosphate tabs \\
\hline
\end{tabular}

\section{References}

1 Stimson GV. Doctor-patient interaction and some problems for prescribing. $7 \mathrm{R}$ Coll Gen Prac 1976;26(suppl 1):88-96.

2 Hall D. Prescribing as social exchange. In Mapes R, ed. Prescribing practice and drug use. London Croom Helm, 1980:39-57.

3 Mapes RE, Williams WO. The changing pattern of general practitioner drug prescribing in the NHS in England from 1970 to 1975. I R Coll Gen Pract 1979;25:406-12.

4 Anonymous. Secretary of State limits range of prescribable NHS drugs. Br Med $\mathcal{F}$ 1984;289. 1388-9. 
5 Informal Working Group on Effective Prescribing. Report. London: DHSS, 1983. (Greenfield

report.)
6 Murdoch JC. The epidemiology of prescribing in an urban general practice. $\mathcal{F} R$ Coll Gen Pract 1980;30:593-602.

7 Skegg DCG, Doll R, Perry J. Use of medicines in general practice. Br Med J 1977;i: 151-63.

8 Hamley JG, Brown SV, Crooks J, Knox JDE, Murdoch JC, Patterson AW. Prescribing in general practice and the provision of drug information. $f R$ Coll Gen Pract 1981;31:654-60.

9 Sheldon MG. Seif audit of prescribing habits and clinical care in general practice. $f(R \mathrm{Coll} G e n$ Pract 1979;29:703-11

10 Flemming DM. An epidemiological method applied to practices to measure the representativeness of their prescribing characteristics. Br Med $\mathcal{f}$ 1984;289:1425-8.

11 Harris CM, Jarman B, Woodman E, Whyte P, Fry JS. Prescribing-a suitable case for treatment. Occasional paper 24. London: Royal College of General Practitioners, 1984.

12 Brodie MJ, Eccles S, Harrison PI. Prescribing in general practice: pharmacological approach. $\mathrm{Br}$ Med f 1983;286:941-4.
13 Jolles M. Why not compile your own formulary? J R Coll Gen Pract 1981;31:372.

14 Whyte A. How we streamline our scrips. Medical Economics 1985;6(1):24-6.

15 Ryde D. Prescribing - a controversial craft? Practitioner 1981;225:283-5.

16 Hemminki E. Review of literature on the factors affecting drug prescribing. Soc Sci Med 1975;9:111-6.

17 Melville A. Job satisfaction in general practice: implications for prescribing. Soc Sci Med $1980 ; 14 a, 495-9$.

18 Howie JGR. Clinical judgment and antibiotic prescribing in general practice. $\mathrm{Br}$ Med $\mathcal{J}$ $1976 ;$;i: $1061-4$

19 Lennard HL, Cooperstock R. The social context and function of tranquillizer prescribing. In Mapes R, ed. Prescribing practice and drug use. London: Croom Helm, 1980:73-82.

20 Renieri A, Piperno A. Factors affecting list size of general practitioners and number of drugs prescribed: findings of a recent study. Soc Sci Med 1983;17:335-41.

(Accepted 25 fanuary 1985)

\title{
Style Matters
}

\section{PEARLS (personally arranged learning sessions): an alternative to presentations of free papers}

\author{
P L SCHWARTZ, C J HEATH
}

\begin{abstract}
"For our students, we have thrown the lecture into outer darkness, as an outworn remnant of an earlier pedagogic era; but for ourselves, we teachers continue to lecture to each other, almost incessantly. We dash all around the country, indeed half way around the world, winter and summer, spring and fall, leaving our appointed tasks-such as teaching students-and when we get there, what do we do? We sit down and listen to lectures, or, worse still, we stand up and give them."
\end{abstract}

Richards is not the only one to voice such complaints. Others have decried the poor standards of communication, ${ }^{2-4}$ the loss of excitement and person to person contact, ${ }^{5}$ and the excessive use of brief verbal presentations of contributed papers at scientific meetings. ${ }^{5-7}$ A few suggestions for alternatives to open paper presentations have been made recently. ${ }^{67}$ We describe a new approach that was used at a combined meeting of the Australasian and New Zealand Association for Medical Education and the Association of Australian and New Zealand University Dental School Teachers.

\section{Background and method}

During the early stages of preparation for a conference of the Australasian and New Zealand Association for Medical Education and the Association of Australian and New Zealand University Dental School Teachers that was held in Dunedin in August 1984 one of us (PLS) proposed a radical departure from standard practice to change the two afternoons ordinarily devoted to presentations of free papers or conventional workshops. Reasons for this were dissatisfaction with the passivity of the audiences at presentations of papers, the poor quality of many presentations, and the lack of

\footnotetext{
Department of Clinical Biochemistry and Dean's Department, University of Otago Medical School, Dunedin, New Zealand

P L SCHWARTZ, MD, senior lecturer

C J HEATH, MB, DPHIL, associate dean for undergraduate stlidies

Correspondence to: Dr P L Schwartz.
}

relevance of much of what was presented. Most value can be gained from conferences by identifying specific questions or problems and making contact with individuals or small groups who have ideas or experience in those areas. It was suggested that such contacts should be formalised as the main afternoon activity of the conference. The local organising committee accepted the suggestion with enthusiasm.

To emphasise that these sessions were to be opportunities for registrants to share ideas and experiences, and that each registrant could expect to get some highly relevant personal information from them, it was suggested that they be called PEARLS (PErsonally ARranged Learning Sessions).

At the time of formal postal registration each registrant was asked to list the topics he (or she) wished to learn about, to give brief details of each one he would offer, and to specify the maximum number of people he wished to work with in each session he offered.

Soon after the deadline for returns all the information on topics offered was collated and listed in the conference programme, which was circulated to all registrants two to three weeks before the conference. Each person was asked to look over the list of topics and to be prepared to choose among them on arrival at the conference.

We divided the two afternoons into nine intervals of half an hour or an hour. Nine index cards $(127 \times 76 \mathrm{~mm})$ were prepared for each registrant. Each card was labelled with the registrant's name and affiliation and stamped and colour coded to correspond to one of the nine intervals.

The sessions being offered were distributed throughout the two afternoons so that there were roughly equal numbers of sessions running during each time interval, with a wide variety of topics. Portable bulletin boards $(1 \cdot 2 \times 2 \cdot 4 \mathrm{~m})$ were used to post the details, one section of board being devoted to each time interval with a labelled space for each session being offered. Each session was headed by a card listing the experience of the session leader(s). Registrants were to attach their cards with map pins limited to the number that the session leader had specified as the maximum for his group (at most 12). For each time interval there was a pocket for "uncommitted" cards-that is, those from registrants who did not want to attend any of the sessions offered during that time or who wished to have afternoon tea or to go somewhere else. Board space (as well as rooms and other facilities) was also provided for "special 